\title{
From supply chain integration to operational performance: the moderating effect of market uncertainty
}

\begin{abstract}
This research examines the moderating effect of market uncertainty on the causal effects from supply chain integration to operational performance of a typical supply chain. Based on an extensive and critical literature review, two exploratory conceptual hypotheses have been developed for the non-linear relationship between the supply chain integration and operational performance of the original equipment manufacturer; and how may that relationship be moderated by a specific construct of market uncertainty. Empirical survey instrument has been designed and applied to gather the data from a wide spectrum of automotive industry in China. Confirmative factor analysis and threshold regression analysis were used as the primary research methodology to test the hypotheses. We find strong support to the hypotheses from the empirical evidence, which leads to the finding that the relationship between the supply chain integration and operational performance is 'non-linear', and the 'non-linearity' can be significantly moderated by the market uncertainty as one of the key environmental factors for the supply chain. This study extends the current literature by contributing for the first time the discussion of an analytical model that represents the causal effects from supply chain integration to its operational performance with respect to the market uncertainty as a moderating factor.
\end{abstract}

Key words: Automotive industry; market uncertainty; operational performance; supply chain integration; supply chain management.

\section{Introduction}

Researchers have long articulated the necessity of a close integration between manufacturers and their suppliers and customers in attempt to deliver the supply chain's optimum performance (Tavakoli et al. 2012; Flynn et al. 2010; Turkulainen and Ketokivi 2012; Zhao et al. 2013; Huang et al. 2014; Prajogo et al. 2015). The degree of interactions between the participating member of the supply chain and the appropriate inter-relationship postures have 
become the widely acknowledged key enablers for supply chain success (Tyagi, et al., 2015). Supply chain integration and its processes that help to develop high level collaboration and partnership with supplier and buyer have been regarded as the undisputable factors for supply chain success (Droge et al. 2012; Wilden et al. 2013;). However, with the increased supply chain complexity and sprawling global diversity over the last decade, there has been a call to rethink the universal necessity as well as the theoretical validity of supply chain integration (SCI) under the renewed business environment in respect to its highly acclaimed contribution to the supply chain's competitive performance (Lambert and Cooper 2000; Asian et al. 2009; Liu and Cruz 2012; Huang et al. 2014; D. I. Prajogo et al. 2015; Sharifkhani et al. 2016; Somarin et al. 2017(a)).

We argue that it is far from being certain that the level of the SCI integration will always be positively correlated with the optimum performance (Graham et al. 2005; Wook Kim 2006; Kim 2009). However, evidently, many previous researches appear to have been inconsistent or even conflicting with one another about their findings (Devaraj et al. 2007; Gimenez et al. 2012; Sousa et al. 2012). Although, some of the findings on such positive relationship might be assumed to be restricted to certain specific conditions (Cao et al. 2015; Ebrahimi 2015), many others were intended to be general on their findings (Bowersox et al. 1999). No one, however, appear to have attempted any form of analytical model to depict the inter-play of supply chain integration (SCI), operational performance (OP) along with exogenous control factors in the business environment. Without an analytical model, the research findings on the relationship between SCI and other constructs often tends to be fragmented and inconsistent (Flynn et al. 2010; Turkulainen and Ketokivi 2012). Arguably, a properly derived analytical model, if achievable, will provide a more holistic and detailed explanation to the problem than a formative evaluation.

Extant literature also indicates that the level of SCI and its contribution to the manufacturer's performance are subject to the influence of various exogenous and endogenous factors (Turkulainen 2008; E. M. Wong et al. 2011; Gimenez et al. 2012). In particular, the recent advent of the open source information system has made SCI and its influence to supply chain performance more susceptible to the exogenous factors (Boehmke and Hazen, 2017). These factors may include ones such as competitiveness of the supply chain's product; market uncertainty; national culture, technological environment, and even organisational 
characteristics. What may be agreeable without being taken into too much controversy is that any attempt to construct a universally applicable relationship/correlation model between SCI and OP is likely to be doomed theoretically. However, what has not been agreed, or still remain inconclusive, is that how the relationship between SCI and OP may be influenced and by which factors (Van der Vaart and van Donk 2008). This inconclusiveness therefore logically gives rise to the research gap in the SCI related subject areas.

In the light of addressing the research problem raised, the intention of this study is to take a small step forward but in the right direction towards addressing the problem. We define a manageable scope that covers only three key constructs: SCI, OP and Market Uncertainty (MU), and attempt to model the relationship in between them analytically. The validity of our choices of the three key constructs for the study will be discussed in the next section.

Thus, the objective of this study is to revisit the causal relationship between the supply chain integration (SCI) and the manufacturer's operational performance (OP) under the full spectrum of market uncertainty (MU) as the exogenous moderating factor; and by using an empirical instrument to create an analytical model that further depicts and explains the interplay of those three constructs. The unit of analysis of this study is defined as the manufacturer that act as the OEM (original Equipment Manufacturer) in the supply chain. The focus is pitched at the dynamic relationship between SCI and OP.

Our research starts with the identification of the research problems through literature review. Based on some further synthesising of a cluster of more relevant literatures, hypotheses have been developed to attempt a conceptual advancement in terms of the relationship between SCI and OP under the influencing factor of market uncertainty (MU). To rigorously test the hypotheses, the threshold regression methodology has been applied on to the empirically collected data from selected companies in the Chinese automotive industry. Finally, some concluding remarks are drawn from the discussion of the findings.

Despite the acclaimed theoretical contribution, the research is also intended to benefit the front line practitioner by guiding them to anticipate varied levels of performance effects on supply chain integration, which are dependent on the moderating effect of the market 
uncertainty they are facing. The research finding could also offer some pragmatic guidance on how to achieve performance oriented supply chain integration.

The remainder of the paper is organised as follows. Section 2 illustrates the theoretical background of the issues in concern and lead to a number of identified research gaps, based on which two hypotheses have been developed. Section 3 , is devoted to the choice and description of the methodology applied, including questionnaire design, data collection and data validation, threshold regression process. Section 4 shows the detailed quantitative results from the threshold regress processes. Section 5 discussed results in respect to the hypotheses and clarifies the key findings. Finally, in Section 6, a number of conclusions are drawn, whereby the novelty and value of the research are further underlined.

\section{Theoretical Background}

\subsection{Supply chain integration (SCI)}

Supply chain integration (SCI) is one of the widely researched topics in the field of supply chain management. All researchers seem to have agreed that SCI is a critical construct that has profound implication to the manufacturer's performance (Huo 2012; D. Prajogo and Olhager 2012; Turkulainen and Ketokivi 2012; L. Zhao et al. 2013; Huang et al. 2014; Ebrahimi 2015). Most researchers seem to have subscribed the concept that SCI promotes positively the supply chain competitive strength and sustainable growth (Rai et al. 2006; Won Lee et al. 2007; Huo 2012). However, literature evidences also show that there are still disputes, including those around its basic definitions. Some define the SCI as the integration between the manufacturer and its suppliers (Huang et al. 2014), others define it as the manufacturer's external integration that includes supplier and customer (Huo 2012); and yet others define it in the three dimensions of supplier integration, internal integration and customer integration (Flynn et al. 2010). Some researches focus on the individual component dimension of the SCI (Graham et al. 2005), and the others focus on the SCI as a single overarching construct (Rai et al. 2006). Notwithstanding the merits of each of those arguments, we choose the definition offered by Flynn et al. (2010), which constitutes supplier, internal, and customer integrations. Subsequently, our empirical data collection on the 
measurement indicators/variables of SCI will be targeted at those three dimensions accordingly.

Knowing full well that there have been different approaches towards the modelling of SCI, our choice to emphasise on a single latent factor for SCI does not necessarily contravene with the researches that prefer to focus on the individual sub-level components of the SCI. It is the matter of research preferences as far as the literatures appears to demonstrate. Both approaches have their merits. We argue that the diverse dimensions of SCI and a multitude of measures of SCI can ultimately be represented by a latent factor (still call it SCI in our model later), which is a relatively convenient way for the investigation. Such a "dimensional reduction" approach in conceptual modelling has been proven effective in many past researches (Schreiber et al. 2006; Coleman 2011; Brown 2015;).

\subsection{Operational performance $(O P)$}

Operational performance (OP) is a key enabler to the overall supply chain performance, which usually is the amalgamated outcome from multiple factors and enablers in the system. Van Hoek (1998) and Beamon (1999) suggested that performance measures for a supply chain should include indicators in the operational dimension, such as customer satisfaction and the operational responsiveness to the changing market demand. Similarly, Neely et al. (1995) enlisted cost, time, quality, delivery and flexibility as the basic measures of operational performance. While addressing the needs for supply chains to balance their attention to the environmental concerns, Jakhar (2015) developed a green supply chain operational performance framework.

We choose $O P$ as one of the constructs for this study for two reasons. One is because we see strong evidence that OP is a major enabler of supply chain performance, which draws great deal of attentions from the research community (Devaraj et al. 2007; C. Y. Wong et al. 2011); the other is because OP is a measurable construct, which could be influenced by the level of SCI. Furthermore, there is little doubt, OP is a critical and indispensable part of many performance measurement frameworks witnessed in today's literature ( $\mathrm{Yu}$ et al. 2014; Ebrahimi 2015), albeit their findings are not always consistent with each other. 
One may question why not use 'business performance' or 'supply chain performance' instead? Well, 'business performance' involves more environmental influences, including competitors, and infrastructure (Goldman 1995), while OP is more internal and can be isolated relatively neatly to the effects from SCI. For 'supply chain performance', it is somewhat beyond our defined 'unit of analysis', which is the manufacturer; also the conceptual scope of 'supply chain performance' can be ambiguous and blurry. However, we admit, for the purpose of this study more constructs can be and should be explored in the future.

\subsection{Market uncertainty (MU)}

Contingency theory (Lawrence and Lorsch 1967; Thompson 1967) suggests that no theoretical models can possibly be universally true at all time. There will be no one-size-fitall solution to supply chain development (Scott and Cole 2000). Hence, one can deduce that the relationship model of SCI with OP may never existed until or unless we apply one or more contingency conditions. The contingency theory may have also explained why many relationship models between SCI and OP are apparently conflicting with each other (Wang, et al., 2011). Thus, for this study, the causal relationship between SCI and OP is to be researched under the specific moderating effect of an external contingency factor - market uncertainty (MU).

For the purpose of this study, MU as one of the environmental factors appears to have high priority amongst the others. Automotive industry in China, in particular, faces strategic and operational challenges due to the increased market uncertainty in the recent years (Somarin et al. 2016; Somarin et al. 2017(b); Faghih-Roohi et al. 2016; Asian and Nie 2014, Ansaripoor et al. 2017; Paul et al. 2017;). Shalender and Singh (2015) proposed conceptual framework to address the critical significance of market uncertainty and how company should respond to it flexibly, especially in the automotive industries. Diverse product ranges receive a wide spectrum of domestic market responses. Some can be categorised as the stable markets, others dynamic ones, subject to the stage of product life cycle and / or consumer market segmentation (Lockstroem et al. 2010). Evidently, MU has become one of the key variables that influence the supply chain strategy and operational performances. 
To develop a conceptual framework that encapsulate the above mentioned three key constructs, we resort to a number of well-established theories. Contingency theory stipulates there is no theory that is always correct. Theories tend to be contingent to one or more external factors that moderates or controls the behaviour of the system. Thus, we take the market uncertainty as one of the key exogenous factors that may largely govern the relationship between SCI and OP. MU is an external environmental factor and its behaviour is beyond management control. MU is normally manifested in 'Fluctuation of demand', 'price elasticity', 'seasonality changes' and so on. MU is also one of the widely researched and highly documented factors that appears to draw good level of attentions in the literature (; C. Y. Wong et al. 2011; He and Zhao 2012; Longinidis and Georgiadis 2013; Huang et al. 2014).

\subsection{Relationship of SCI to OP}

Our literature review shows that many previous research have already addressed the relationship between SCI and performance (D. I. Prajogo et al. 2015; Ebrahimi 2015; G. Zhao et al. 2015). However, their findings are not always consistent. Appendix A listed a selection of recent articles in regards to their findings on the relationship between SCI and OP.

Configuration theory (Cao et al. 2015) suggests that how successful the patterns of SCI would be related to the operational performance in different configurations. It argues that organizations perform better when they develop better configurations of interconnected elements ( Drazin and Van de Ven 1985; Sinha and Van de Ven 2005). It is therefore suggested that a highly integrated supply chain in this sense is likely to perform well in the market place. Configuration theory underlines the necessity for a supply chain to be well integrated in order to deliver high performance. It is thus reasonable to extrapolate that the configuration theory provides a theoretical support for the causality from SCI to OP.

Structural contingency theory (; Lawrence and Lorsch 1967; Galbraith 1973; Chandler 1990) suggests that how well a supply chain perform depends on the extent to which the strategy is aligned with its structural design. An even more succinct interpretation of the theory is that the supply chain performance is always contingent upon supply chain structures. However, the theory does not specify how SCI and performance should be aligned with each other. Our 
literature review shows, unfortunately, there have been some significant inconsistencies. Based on our definition of SCI, we reviewed research findings in areas of customer integration, internal integration and supplier integration respectively.

Literature findings in the field of customer integration has been largely consistent. Since customer integration could and have already generated ample opportunities to enables manufacturers to reduce costs, create greater value and detect demand changes more responsively. Customer integration has long been recognised as a pivotal factor to customer satisfaction (Won Lee et al. 2007) through which product innovation is often achieved (Song and Di Benedetto 2008; Koufteros et al. 2005). On the other hand, some researchers find customer integration does not necessarily contribute to supply chain performance (Devaraj et al. 2007; Jonsson et al. 2011; Turkulainen and Ketokivi 2012; ).

Browsing through the literatures on internal integration, discrepancies are equally apparent. Some authors found there is no direct relationship between internal integration and the operational performance of the manufacturer (Koufteros et al. 2005; Gimenez and Ventura 2005); others found that there is a positive relationship between the internal integration and the operational performance, including the performance on process efficiency (Saeed et al. 2005) and logistics service (Stank et al. 2001; Germain and Iyer 2006).

Reviewing the literatures findings on the supplier integration has also revealed non-trivial inconsistencies. In some literatures supplier integration has been found to be related to new product introduction processes and product development performance (Koufteros et al. 2005; Petersen et al. 2005;) and supplier development and visibility related measures (Cousins and Menguc 2006). Others, however, have found no significant correlation between supplier integration and operational performance (Stank et al. 2001), or even found a slightly negative relationship (Stank et al. 2001; Koufteros et al. 2005; Swink et al. 2007).

Another area of controversy in the literature is whether SCI should be modelled with the operational performance in general without constraint. For example, Bowersox et al. (1999) discussed the critical factor of SCI without mentioning of any contingency to the finding. Their finding claims that SCI is the centre piece of overall performance, which implies a positive correlation between the two. Our critiques, however, is that there are evidences to 
suggest the contrary, i.e. sometimes SCI is not positively correlated with supply chain's overall performance (Koufteros et al. 2005; Swink and Song 2007).

Admittedly, many previous researchers were in the same vein as Bowersox's that SCI always positively relates and contributes to the supply chain overall performance. However, equally convincingly, other researchers have demonstrated specifically a non-positive and even slightly negative correlations between the SCI and overall performance. Appendix-A lists the publications that have conflicting opinions on the relationship between the SCI and performance. Such is the status of inconsistency in the concurrent literature, which give rise to the validity of the research problem.

Based on above literature review, we hypothesise the following:

1. The overall pattern of correlation between the supply chain integration and operational performance tends to be 'non-linear', i.e. not always proportionally correlated.

2. The nature of the 'non-linearity' between the supply chain integration and operational performance is significantly influenced by the market uncertainty.

The first hypothesis is drawn on the basis that SCI, as widely recognised in the literature, has an undeniable and often significant contributions to the operational performances of a supply chain. However, the apparent causal relationship from the degree of SCI to the level of OP is not simplistically a 'linear one.' It varies in accordance with the exogenous circumstance. According to the dynamic capability view (Teece, et al., 1997), the competitive advantage of a supply chain is believed to be rested on a series of distinctive dynamic ways of coordinating and combining the supply chain's specific asset that also fit to its position in the competitive environment. SCI is such a way that may (or may not) deliver the fit to its competitive environment where heterogeneous factors interacts.

The second hypothesis is drawn on the basis that, given the first hypothesis above, the primary influencing factor for the causality between SCI and OP could be the market uncertainty for the specific supply chain market in question. The MU factor here is defined as a demand uncertainty, which often is directly linked to and perhaps measured by the level of 
market satisfaction within a given standard of OP. Based on the transactional cost economics (TCE) theory (Williamson, 1989), one of the ultimate management objective is to minimise the transactional cost throughout the entire supply chain; and managers should do so by first of all identifying the market price (or the changes of it) of the product stream in question (Williamson, 1991). This underlines one of the theoretical basis that the supply chain success measured in transaction cost economics has to be contingent to the market dynamics and market uncertainty.

Through a carefully designed empirical study and hypothesis testing process shown in the remainder of the paper, we anticipate to contribute to the existing literature with a new conceptual model of the moderated relationship between SCI and OP subject to MU.

\section{Research Methodology}

To test the proposed hypotheses, we identified the automotive manufacturing companies in China (Xinqiao, P. \& Junfeng, W. 2001) as our data gathering field, because China is perhaps one of the biggest automotive markets and also the largest automobile producing country in the world. China has demonstrated a landmark transformation over the last two decades (Flynn et al. 2010; Mozur 2014; Aláez - Aller and Carlos Longás - García 2010). The scope and diversity of China's automotive industry, in terms of product ranges and their market uncertainty (J. Li et al. 2014) have made it attractive to this research. Furthermore, due to the increasingly inextricable connections to the world economy, China's automotive industry is maturing rapidly (Lockstroem et al. 2010). Its implication in the development of automotive supply chain management could be profound. Our purpose for taking the data sample from just one automotive industrial sector is to avoid unnecessary complications that may arise from the inconsistent market behaviors and managerial patterns of different industries, which may confound the already complicated research problem even further. Notwithstanding that the research of similar problems across different industries could also be perhaps equally beneficial, but, it would be an entirely different project altogether.

\subsection{Questionnaire design and measures}


We use questionnaire as one of the main empirical instruments for data collection from a carefully selected group of Chines automotive manufacturers across the country. They are original equipment manufacturers (OEM) to their respective automotive supply chains. The questionnaire was developed in three steps. First, the measures and indicators of the three key constructs, SCI, OP, and MU were defined based on what has been established in the existing literature. We adopted the SCI measures against Narasimhan and Kim (2002) and Cao et al. (2015); OP measures against Frohlich and Westbrook (2001) and Vickery et al. (2003); and MU measures from Huang et al. (2014) and Jonsson et al. (2011). Second, we managed semistructured online video interviews with relevant executives and managers to validate the questionnaire design. Third, a pre-test process was carried out in 20 selected companies to further assure the validity of the questionnaire. The indicators (measurement variables) were all measured using a seven-point Likert scale (Khazaei Pool et al. 2017a). The complete scales are listed in Appendix B.

Our questionnaire was originally developed in English, then translated into simplified Chinese (for mainland Chinese use) by two operations management professors in China. Then, they were translated back into English by another two management specialists (to ensure validity), and the translated English version was checked against the original English version for discrepancies (Khazaei Pool et al. 2017b).

\subsection{Sampling and data collection}

To ensure a more representative sample group of manufacturing companies were selected, we contacted the China Automotive Association to obtain registered manufacturers. We selected the companies through an impartial sampling process which is carried out more or less randomly. As a result, 65 companies have been selected and follow up contact made via phone calls initially. A profile of those sample companies is presented in Table 1.

We tried a new 'Network Approach' in order to improve the survey response rate. Firstly, the questionnaire with a cover letter highlighting the study's objectives were created into a web version (still need to send an email to the respondent to get started) which can be easily accessed and filled by using either a computer or a mobile phone at any time. Second, after all questionnaires were completed and approved by the relevant directors/CEOs of each of 
the 65 sample companies, we set up several chat groups involving all respondents via Wechat (the most widely used communication application in China) mobile application. The chat groups were aimed to gather further opinions regarding our questionnaire, but also significantly increased their response rate.A total of 477 returns were received from the 700 questionnaires sent outachieving a return rate of $68.1 \%$, within which 120 were invalid, yielding a total of 357 valid responses, which represents a valid response rate of $51 \%$. We estimated the nonresponse bias by using a t-test, comparing the early and late responses (Gimenez et al. 2012; Sousa et al. 2012). No significant nonresponse bias was found. A profile of the respondents is shown in Table 2. The respondents group was regarded as credible since more than half of them have had at least 3-year of managerial experience.

Table 1: Profiles of sample companies

\begin{tabular}{lccccc}
\hline Number of Employees & Count & Percent & Annual Income (billion Yuan) & Count & Percent \\
\hline$<200$ & 9 & 14.3 & $10-20$ & 15 & 23.1 \\
$200-500$ & 15 & 23.6 & $20-40$ & 12 & 18.8 \\
$500-1000$ & 16 & 24.6 & $40-60$ & 9 & 13.8 \\
$1000-2000$ & 14 & 21.7 & $60-100$ & 13 & 20.0 \\
$>2000$ & 11 & 15.8 & $>100$ & 16 & 24.3 \\
Total & 65 & 100.0 & & 65 & 100.0 \\
\end{tabular}

Table 2: Respondent features

\begin{tabular}{lclc}
\hline Position & \% of respondents & Years in current position & \% of respondents \\
\hline Chief officer & 10.9 & Over 12 years & 9.3 \\
Director & 22.9 & $7-12$ years & 14.1 \\
Senior manager & 36.4 & $3-7$ years & 36.3 \\
Junior manager & 29.8 & $1-3$ years & 40.3 \\
\hline
\end{tabular}


To further mitigate the potential common method bias (CMB), CFA marker technique (Williams, et al., 2010) has been performed on all 15 indicators. The test results indicate no significant presence of single common factor. To further evaluate the CMB, we applied confirmatory factor analysis (CFA) (Gimenez et al. 2012; Huo 2012) with the null hypothesis model being that all measurement variables were assigned to a single latent variable. The result comes with: $\chi^{2}=668.552, d f=87, \chi^{2} / d f=7.68, \mathrm{GFI}=0.75, \mathrm{AGFI}=0.68, \mathrm{CFI}=0.6$, $\mathrm{RMSEA}=0.21, \mathrm{SRMR}=0.18$, showing that the null model is not built on the data set. Thus, CMB should not be an issue.

\subsection{Reliability and Validity}

Then, we test the reliability of each constructs (SCI, OP and MU), employing Cronbach's alpha that assesses the scale reliability; and followed by a corrected item-total correlation (CITC) reliability test as suggested by Henrysson (1963). The value of estimated Cronbach's alpha is ranging from 0.789 to 0.889 , which is greater than the benchmark value of 0.7 (Cronbach 1951; Tan 2009). In addition, the values of CITC test are all over the cut-off value of 0.3 (see Table 3). Thus, the item scales seem to be reliable enough.

The missing data issue in our sampling process appears to be miner, and thus it has been treated by the Average Imputation method. In order to test the validity of the data we start with Kaiser-Meyer-Olkin (KMO) measure and Bartlett's test of sphericity. Bartlett's test is to check whether we can reject the null hypothesis that the correlation matrix is not an identity matrix. In our analysis, we have a strong evidence $(p<0.001)$ to reject the null hypothesis and therefore prefer the alternative one with $\mathrm{KMO}$ values ranging from $0.787 \sim 0.842$, which is greater than 0.5. The convergent validity is tested by using CFA models (Schreiber et al. 2006). In the CFA model, all items are linked to their corresponding latent variables. The resultant loadings and their $t$-values of each item are safely greater than 0.5 and 2 respectively indicating the convergent validity (Russell 1978). For discriminant validity we apply average variance extracted (AVE) for this study. As suggested by Farrell (2010), a value of the AVE that is greater than 0.5 will indicate an adequate discriminant validity. Our AVE ranges from $0.63 \sim 0.74$ (Table 3). 
Table 3: Reliability and validity analysis with factor scores

\begin{tabular}{|c|c|c|c|c|c|c|c|c|c|c|c|c|}
\hline Items & Mean & $\mathrm{SD}$ & $\begin{array}{c}\text { Factor } \\
\text { Loading }\end{array}$ & t-value & CITC & $\begin{array}{c}\text { Cronbach's } \\
\text { alpha }\end{array}$ & $\begin{array}{c}\text { KMO } \\
\text { and } \\
\text { Bartlettis }\end{array}$ & $\begin{array}{c}\text { Chi- } \\
\text { square }\end{array}$ & $\mathrm{df}$ & $\begin{array}{c}\text { Chi- } \\
\text { square/df }\end{array}$ & AVE & $\begin{array}{l}\text { Factor } \\
\text { Score }\end{array}$ \\
\hline Operational performance (OP) & & & & & & 0.840 & $0.847 *$ & 13.91 & 5 & 2.8 & 0.63 & \\
\hline Y1: & 4.20 & 1.67 & $0.773 *$ & omitted & 0.635 & & & & & & & 0.251 \\
\hline Y2: & 4.09 & 1.30 & $0.829 *$ & 12.746 & 0.707 & & & & & & & 0.270 \\
\hline Y3: & 4.18 & 1.49 & $0.747^{*}$ & 10.989 & 0.604 & & & & & & & 0.243 \\
\hline Y4: & 4.03 & 1.45 & $0.809 *$ & 12.316 & 0.675 & & & & & & & 0.263 \\
\hline Y 5: & 4.06 & 1.60 & $0.758 *$ & 11.336 & 0.613 & & & & & & & 0.247 \\
\hline Supply chain integration (SCI) & & & & & & 0.921 & $0.831 *$ & 21.82 & 9 & 2.42 & 0.72 & \\
\hline X1: & 3.29 & 1.42 & $0.846^{*}$ & omitted & 0.777 & & & & & & & 0.196 \\
\hline X2: & 3.83 & 1.44 & $0.736^{*}$ & 12.313 & 0.637 & & & & & & & 0.171 \\
\hline X3: & 4.23 & 1.51 & $0.870 *$ & 16.797 & 0.806 & & & & & & & 0.202 \\
\hline $\mathrm{X} 4$ : & 4.47 & 1.71 & $0.909 *$ & 19.679 & 0.855 & & & & & & & 0.211 \\
\hline X5: & 4.64 & 1.58 & $0.853 *$ & 16.696 & 0.780 & & & & & & & 0.198 \\
\hline X6 : & 4.53 & 1.49 & $0.862 *$ & 18.510 & 0.795 & & & & & & & 0.200 \\
\hline Market uncertainty (MU) & & & & & & 0.782 & $0.779 *$ & 5.5 & 2 & 2.75 & 0.71 & \\
\hline Z1: & 3.89 & 1.55 & $0.795^{*}$ & omitted & 0.610 & & & & & & & 0.328 \\
\hline $\mathrm{Z} 2$ : & 3.45 & 1.61 & $0.770 *$ & 10.296 & 0.577 & & & & & & & 0.318 \\
\hline Z3: & 4.12 & 1.63 & $0.772 *$ & 10.302 & 0.582 & & & & & & & 0.319 \\
\hline Z4: & 4.23 & 1.72 & $0.775^{*}$ & 10.431 & 0.584 & & & & & & & 0.320 \\
\hline Notes: $\mathrm{n}=357 ; * p<0.001$ & & & & & & & & & & & & \\
\hline
\end{tabular}




\subsection{Dimension Reduction}

CFA is used to reduce the 15 measurement variables (indicators) to 3 latent variables: operational performance (OP), supply chain integration (SCI) and market uncertainty (MU). This approach essentially creates the three latent constructs from the 15 measurement indicators by a reflective mode. In a reflective measurement model it is the construct that lead to a change in the indicators. The CFA provides standardized factor score for each measurement. The factor scores are used to determine a measurement's relative standing on the latent dimension (Yusuf et al. 2004; Brown 2015). We use the obtained factor scores (see Table 3) for all the observed variables to generate the data columns of the three latent variables (Flynn et al. 2010; Won Lee et al. 2007; Sezen 2008), on which all the remaining analysis will be based.

As shown in Figure 1 and 2, the independent variable SCI is scatter-plotted against the dependent variable OP, revealing no or little correlation but a heteroscedastic form of the data (Breusch and Pagan 1979; Koenker and Bassett Jr 1982). However, the visual relationship becomes relatively clearer when the exogenous variable MU is shown on a third axis, which indicates statistically that MU has certain explanatory ability on the relationship between OP and SCI. The observation of MU's explanatory ability is consistent with the findings by Huang et al. (2014) and Wong et al. (2011). On investigating the possible 'non-linear' OPSCI relationship, Das et al. (2006) reported a mathematically inversed V-shaped relationship. Terjesen et al. (2012) directly hypothesized an inversed U-shaped relationship, and tested the hypothesis by applying a polynomial multiple regression method. However, one of the obvious weaknesses of their methods is that they were highly subjective in nature. To avoid the subjectivity, we attempted a threshold regression method instead (Hansen 1999). 


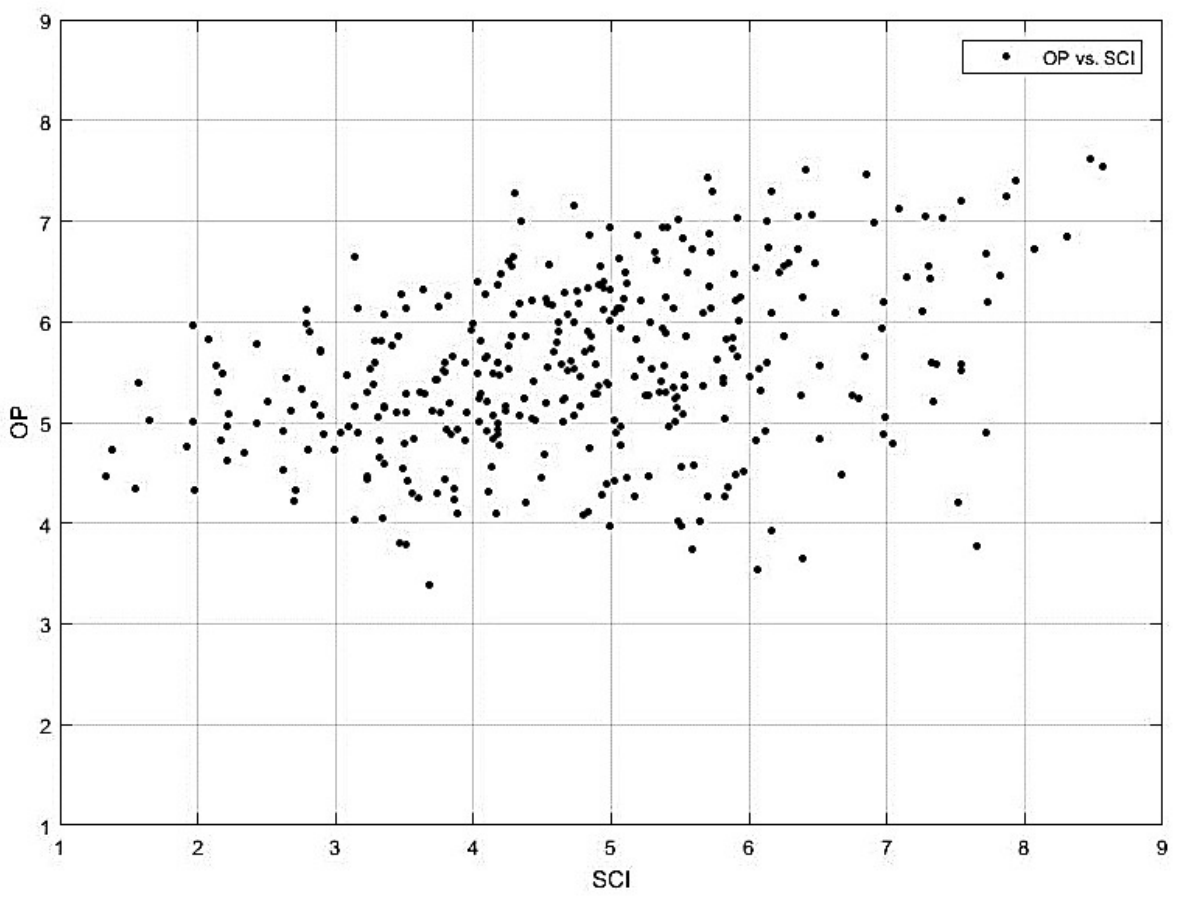

Fig. 1: Scatter plot of OP against SCI

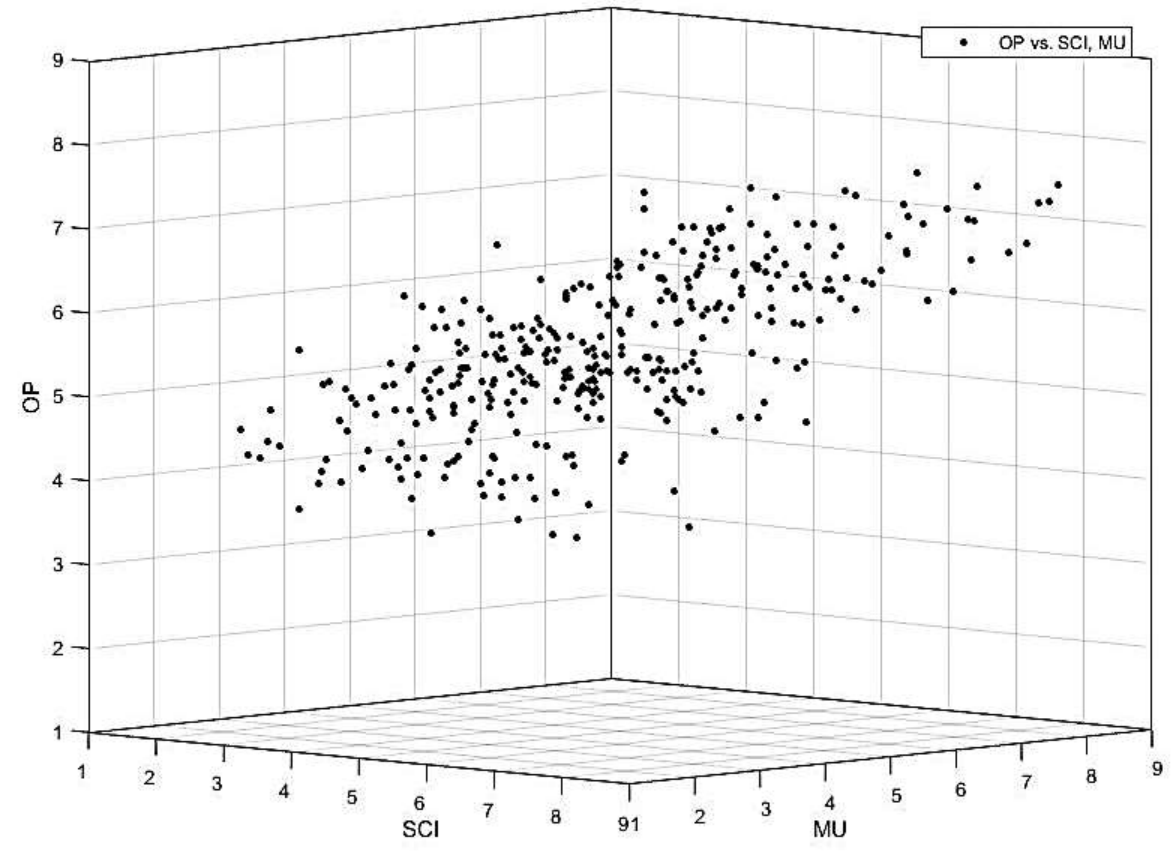

Fig. 2: Scatter plot of OP against SCI and MU 


\subsection{Threshold Regression Analysis}

Threshold regression method is chosen here because it is capable of identifying the underlying thresholds that partition the data into clusters and to model their corresponding correlation through regressions. According to Hansen (1999), threshold regressing method is particularly useful in mitigating the errors caused by subjective factors. It can endogenously divide the data clusters based on the data characteristics. It can estimate and eventually form the distinct patterns of correlation.

The threshold model specified here concerns with the regression between the OP as the dependent variable; and SCI as the independent variable. The critical difference here is that the degree of MU is now used as the threshold variable, which is anticipated to have moderating effect on the relationship between OP and SCI. For a single threshold scenario, following Hansen (1999) study, the single threshold should be constructed as:

$O P_{i}=u_{i}+\beta_{1} S C I_{i} I\left(M U_{i} \leq \gamma\right)+\beta_{2} S C I_{i} I\left(M U_{i}>\gamma\right)+e_{i}$

Where $\beta_{1}$ and $\beta_{2}$ are the coefficients of the regressor SCI; I(.) is the indicator function; represents the unknown threshold to be estimated during the computing process. Based on this model, the observations have now been divided into two 'regimes' (Hansen's choice of word meaning 'regions') depending on whether the threshold variable MU is smaller or greater than the threshold value of $\gamma$. The regimes will then be distinguished by the two regression slopes $\beta_{1}$ and $\beta_{2}$. The residual term $e_{i}$ are assumed to be independent and identically distributed with a zero means and a finite variance of $\sigma^{2}$ and an alternative and more intuitive way of thinking (1) is:

$O P_{i}=\left\{\begin{array}{l}u_{i}+\beta_{1} S C I_{i}+e_{i}, M U_{i} \leq \gamma \\ u_{i}+\beta_{1} S C I_{i}+e_{i}, M U_{i}>\gamma\end{array}\right.$

To deal with the individual effect of $u_{i}$ Hansen (2000) suggests to take averages of the equation (2):

$\overline{O P}_{i}=\beta^{\prime} \overline{S C I}_{l}(\gamma)+\bar{e}_{\iota}$ 
And taking the difference between (2) and (3) yields

$O P_{i}^{*}=\left\{\begin{array}{l}\beta_{1}{ }^{\prime} S C I_{i}{ }^{*}+e_{i}{ }^{*}, M U_{i} \leq \gamma \\ \beta_{2}{ }^{\prime} S C I_{i}{ }^{*}+e_{i}{ }^{*}, M U_{i}>\gamma\end{array}\right.$

The estimation of the slope coefficients $\beta_{1}{ }^{\prime}$ and $\beta_{2}{ }^{\prime}$ is by using the ordinary least square (OLS) method. However, if the null hypothesis $\beta_{1}{ }^{\prime}=\beta_{2}{ }^{\prime}$ has been rejected, as one or more thresholds may exist, the significance tests cannot be calculated under normal distribution. This is called the 'Davies' problem (Davies 2002) which has been studied by Andrews and Ploberger (1994) and Hansen (2000). As they suggested, one can use bootstrap method to simulate the asymptotic distribution of the likelihood ratio tests of the equation (4). The significance level of these likelihood ratio tests determines the number of thresholds. And the confidence interval construction method is introduced by Bai (1997).

With the model (4), we hypothesize that there is a threshold effect along the MU dimension, which forms an asymmetric 'non-linear' relationship between the OP and SCI. It is therefore important to determine whether the threshold effect is statistically significant. To do the test, the null hypothesis and alternative hypothesis for the equation (4) are set as:

$H_{0}: \beta_{1}{ }^{\prime}=\beta_{2}{ }^{\prime}$

$H_{1}: \beta_{1}{ }^{\prime} \neq \beta_{2}{ }^{\prime}$

If the null hypothesis holds, the coefficient $\beta_{1}{ }^{\prime}=\beta_{2}{ }^{\prime}$, indicating that the threshold effect between the OP and SCI does not exist. However, if the null hypothesis is rejected and the alternative hypothesis holds, the coefficient $\beta_{1}{ }^{\prime} \neq \beta_{2}{ }^{\prime}$ indicating that the threshold effect does exist. If there exists the double thresholds, then the model of equation (4) can be modified to:

$O P_{i}^{*}=\left\{\begin{array}{c}\beta_{1}{ }^{\prime} S C I_{i}{ }^{*}+e_{i}{ }^{*}, M U_{i} \leq \gamma_{1} \\ \beta_{2}{ }^{\prime} S C I_{i}{ }^{*}+e_{i}{ }^{*}, \gamma_{1}<M U_{i} \leq \gamma_{2} \\ \beta_{3}{ }^{\prime} S C I_{i}{ }^{*}+e_{i}{ }^{*}, M U_{i}>\gamma_{2}\end{array}\right.$

Where the threshold value $\gamma_{1}<\gamma_{2}$. This can be expanded to multiple threshold models with $\gamma_{1}, \gamma_{2}, \gamma_{3}, \ldots, \gamma_{n}$ 


\section{Results}

Multi-threshold regression analysis described above was used to test both of our hypotheses formulated in section 2. In the first step, the threshold effect of MU on the relationship between OP and SCI was assessed in order to determine whether there was a moderating effect. In the second step, we assessed the relationship between two-way interactions of SCI, SCI square (inverse U-shaped relationship hypothesized by Terjesen et al. (2012)) and MU to OP by applying hierarchical regression (Flynn et al. 2010), for the purpose of providing a comparison between the results of threshold regression analysis and hierarchical regression analysis.

\subsection{Threshold Regression Results}

To determine the number of thresholds, equation (5) was estimated by OLS, allowing for zero to multiple thresholds. The $F$-test statistics F1, F2 and F3, along with their bootstrap $p$-values, are reported in Table 4 . The $F$-tests show that the single threshold effect is highly significant with $p$-value of 0.000 , in addition, the test of a double threshold effect is also strongly significant with $p$-value of 0.003 . By contrast, the test for a triple threshold effect failed to show a strong significance. Thus, we conclude that there is strong and statistically significant evidence to support the existence of two thresholds in the relationship between OP and SCI.

Table 4: Tests for threshold effects

Test for single threshold

F1

99.8

P-value

0.000

$95 \%$ critical value

14.8

Test for double threshold

F2

P-value

0.003

95\% critical value

Test for triple threshold

F3

P-value

0.779

95\% critical value

14.8 
Notes: bootstrap $=2000$

The two estimated threshold values and their 95\% confidence intervals are reported in Table 5. The estimated threshold values are 3.49 and 5.52, which stands on the two sides of the threshold variable mean of 3.98. Thus, the two thresholds divided the MU dimension into three regimes of 'high market uncertainty' (MU $\leqq 3.49)$, 'middle market uncertainty' $(3.49<$ $\mathrm{MU} \leqq 5.52)$, and 'low market uncertainty' (MU > 5.52). Additional information of multi-stage estimation of the threshold values are shown in Figures $3 \& 4$ (a) and (b) below.

Table 5: Threshold estimates

\begin{tabular}{lcc}
\hline & Estimates & $95 \%$ confidence interval \\
\hline$\gamma_{1}$ & 3.49 & {$[3.321,3.556]$} \\
$\gamma_{2}$ & 5.52 & {$[5.501 .5 .546]$} \\
\hline
\end{tabular}

Table 6 reports the number of responses which fall into the three regimes. We see that the number of responses in the 'high market uncertainty' regime is $61(17.1 \%)$, the 'middle market uncertainty' regime involves 173 (48.5\%) and the 'low market uncertainty' regime covers the rest $123(34.4 \%)$ responses.

Table 6: Number of responses in each regime

\begin{tabular}{lc}
\hline Respondents class & Number of responses \\
\hline $\mathrm{MU} \leqq 3.49$ & 61 \\
$3.49<\mathrm{MU} \leqq 5.52$ & 173 \\
$\mathrm{MU}>5.52$ & 123 \\
\hline
\end{tabular}

The regression slope estimates and the conventional OLS standard errors (SE) are displayed in Table 7. The estimated results suggest that SCI is perhaps negatively correlated with OP in the first regime as shown in Figure 3 (a), which could be unexpected to some researchers that such result seems to be counterintuitive and contradictory to the positive relationship established in many integration and performance studies. On the other hand, the estimated slopes become positive in the second and third regimes as shown in Figure 3 (b) and (c), and 
the magnitude of the slopes rise from 0.061 to 0.237 when it shifts from the second to the third regime. Thus, these results appear to support squarely both of our hypotheses.

Table 7: Regression estimates: double threshold model

\begin{tabular}{lcc}
\hline Regressor & Coefficient estimate & OLS SE \\
\hline $\mathrm{SCI}(\mathrm{MU} \leqq 3.49)$ & $-0.196^{* * * *}$ & 0.051 \\
$\mathrm{SCI}(3.49<\mathrm{MU} \leqq 5.52)$ & $0.061 * * *$ & 0.031 \\
$\mathrm{SCI}(\mathrm{MU}>5.52)$ & $0.237^{* * *}$ & 0.025 \\
Notes: $* * * \mathrm{p}<0.01$ & & \\
\hline
\end{tabular}

(a)

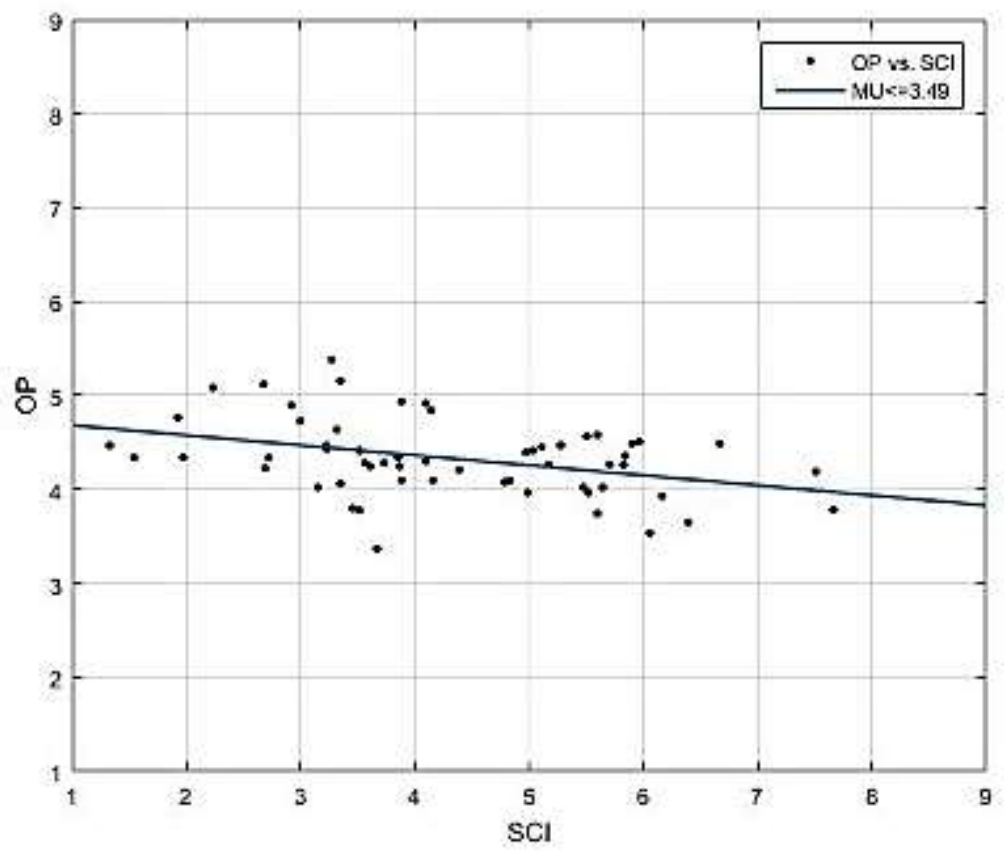

(b)

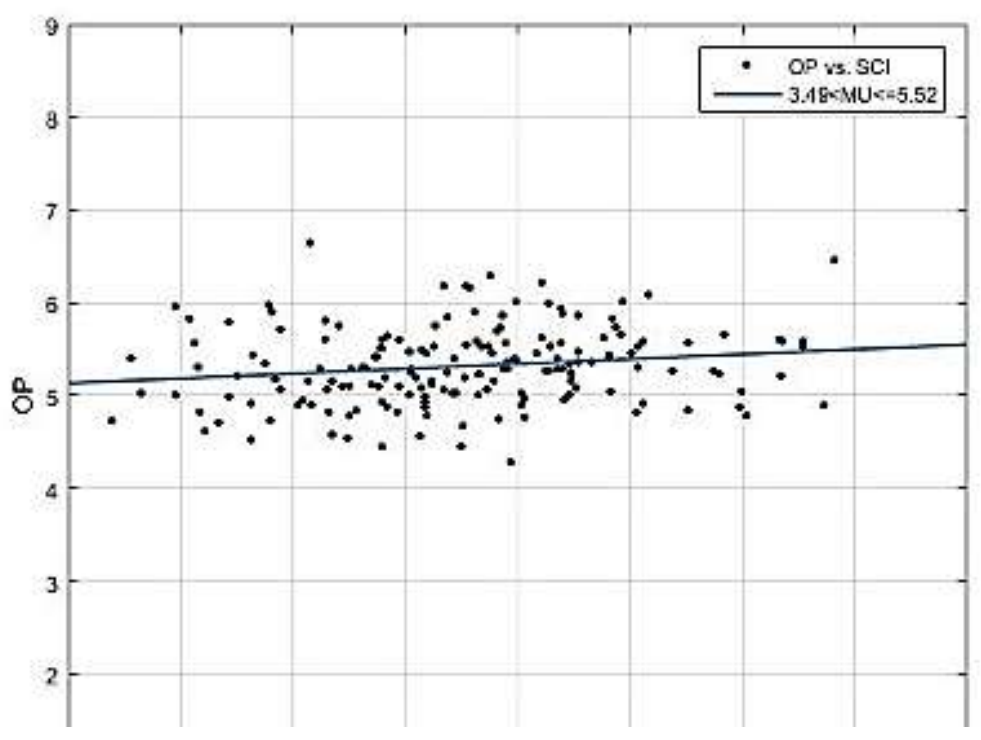


(c)

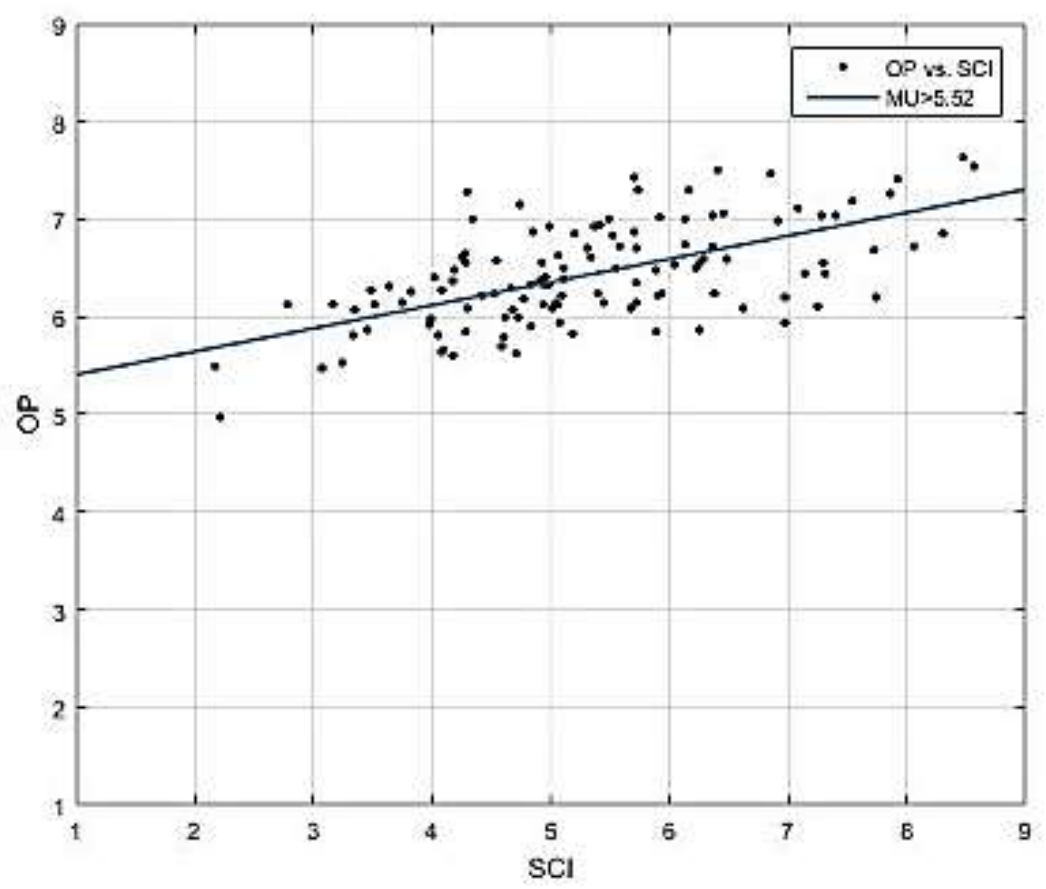

Fig. 3: Scatter plots with regression line in different regimes (a), (b), (c).

\subsection{Hierarchical Regression Results and Comparison}

The results of the hierarchical regression analysis together with the threshold regression results are compared in Table 8. Model 1 represents a significant direct positive relationship between SCI and OP $\left(\beta_{1}\right)$, and between MU and OP $\left(\beta_{2}\right)$. Model 2 includes additional regressors of SCI square $\left(\beta_{3}\right)$, SCI times MU $\left(\beta_{4}\right)$ and squared SCI times MU $\left(\beta_{5}\right)$. Adding those additional regressors yielded a significant change in Adjusted- $R^{2}$, and contributed significantly to its predictive power, which supports the result of Terjesen et al. (2012). However, in Model 3 the predictive power is even higher as the Adjusted- $R^{2}$ reaches 0.612.

As shown in the Table 8 , Model 1 tests the assumption of a universally positive linear relationship between SCI and OP. Such assumption is supported $\left(\beta_{1}=0.075, p<0.01\right)$, although the Adjusted- $R^{2}$ is only 0.143 . Thus, a conclusion of a positive relationship can be drawn based on the results of Model 1. To test the assumption of an inverse U-shape relationship, following Terjesen et al. (2012), Model 2 tested the joint significance of a squared term of SCI and its interactions with MU by applying the hierarchical regression 
method. The results of Model 2 support a slightly inverse U-shaped relationship $\left(\beta_{3}=-0.013\right.$, $p<0.1)$, and they also show that the relationship turns linear when considering $\mathrm{MU}\left(\Omega_{5}=-\right.$ $0.008>\beta_{3}, p<0.1$ ). What is worth mentioning here is that the Adjusted- $\mathrm{R}^{2}$ of the Model 2 is greater than that of the Model $1\left(\Delta\right.$ Adjusted- $\left.R^{2}=0.112\right)$, which means the Model 2 is able to explain additional $11.2 \%$ of the data sample. However, it is still hard for the Model 2 to tell how the three variables (OP, SCI and MU) inter-play with each other. To rip away the hazy veil covered on these three variables, as shown in Figure 3, Model 3 reports the statistically significant regression coefficients of SCI on OP in each of the 3 regimes segmented by MU. In addition, the Model 3 achieved further $35.7 \%$ explanatory power with its Adjusted- $R^{2}$ reaches 0.612 . It is therefore evidently convincing that the Model 3 - the threshold method achieves the highest explanatory power of the SCI-OP relationship.

Table 8: Direct, polynomial and threshold regression results

\begin{tabular}{|c|c|c|c|}
\hline Regressor & Model 1:Direct Effects & $\begin{array}{l}\text { Model 2: Non-linear } \\
\text { Moderating Effects }\end{array}$ & $\begin{array}{l}\text { Model 3: Threshold } \\
\text { Moderating Effects }\end{array}$ \\
\hline $\mathrm{SCI}(\mathrm{A})\left[\beta_{1}\right]$ & $0.075^{* * *}$ & $0.063^{*}$ & \\
\hline $\operatorname{MU}(\mathrm{B})\left[\beta_{2}\right]$ & $0.393 * * *$ & $0.331 * *$ & \\
\hline $\mathrm{A}^{2}\left[\beta_{3}\right]$ & & $-0.013 *$ & \\
\hline $\mathrm{A} * \mathrm{~B}\left[\beta_{4}\right]$ & & $0.057 * *$ & \\
\hline $\mathrm{A}^{2 *} \mathrm{~B}\left[\beta_{5}\right]$ & & $-0.008^{*}$ & \\
\hline $\mathrm{A}(\mathrm{B} \leqq 3.49)\left[\beta_{6}\right]$ & & & $-0.196 * * *$ \\
\hline A $\quad(3.49<\mathrm{B} \leqq 5.52)$ & & & $0.061 * * *$ \\
\hline \multicolumn{4}{|l|}{$\left[ß_{7}\right]$} \\
\hline $\mathrm{A}(\mathrm{B}>5.52)\left[\beta_{8}\right]$ & & & $0.237 * * *$ \\
\hline Intercept & $3.189^{* *}$ & $5.22 *$ & $4.93^{* * *}$ \\
\hline Adjusted- $R^{2}$ & 0.143 & 0.255 & 0.612 \\
\hline$\Delta$ Adjusted- $R^{2}$ & & 0.112 & 0.357 \\
\hline Notes: ${ }^{*} \mathrm{p}<0.1 ; * * \mathrm{p}<0$. & $5,{ }^{* * *} \mathrm{p}<0.01$ & & \\
\hline
\end{tabular}

\section{Discussion}

The above results show that Model 1 is just a simple linear function; and both of our hypotheses were supported by Model 2 and Model 3 respectively (table 8), indicating SCI is 
'non-linearly' related to the OP subject to MU; and the Model 3 (threshold regression analysis) is quite convincingly the most effective approach to show the moderating effect of the exogenous factors. A managerial implication from tis finding could be that before implementing any supply chain integration strategies the market condition must be examined and defined according to the model. Thus, the model helps to set a more realistic expectation to the outcome of the SCI strategies.

Looking again closely at the primary data of the three constructs, when the $3 \mathrm{D}$ data 'cloud' is segmented by the two thresholds into three regimes along the MU dimension, clear regression patterns emerge. Thus, one may begin to see the benefit of applying the threshold regression analysis.

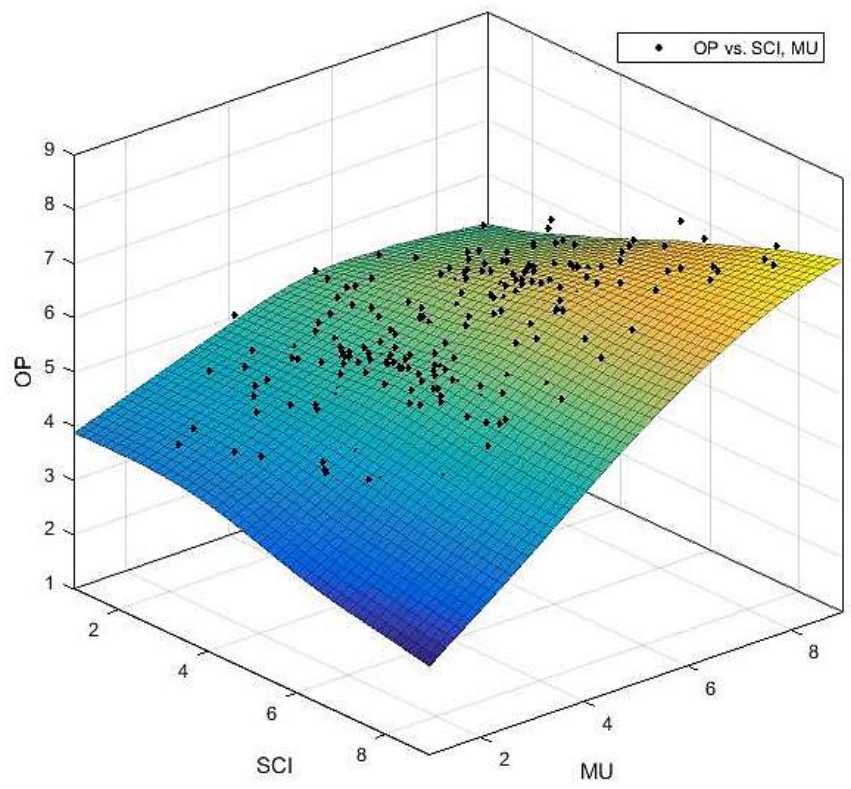

Fig.4: 3D Regression plot.

First, for a given level of SCI, the OP level is always negatively correlated with MU which depicts a negative relation between OP and MU, when the SCI is taken a value of 5 for example. This derived finding from the $3 \mathrm{D}$ model is in fact quite consistent with past research findings that market uncertainty is a negative influencing factor to supply chain operational performance given a constant level of SCI (He and Zhao 2012; Huang et al. 2014). This may be also exemplified by the case when the financial market became uncertain in 2007 , the operational performance of banking supply chains across the world declined sharply. 
Second, given a fixed value of OP, for example as a targeted operational performance, the 3D model will reduce to a model that depicts the relationship between SCI and MU, which shows that the level of integration is somewhat negatively correlated with the level of MU. This is also evident in the past literatures, when in a highly uncertain market place the supply chain tends to strengthen its competitive performance through flexibility and responsiveness, which often means outsourcing and virtual network with reduced vertical integration (Stratton and Warburton 2003).

Third, given a fixed level of MU, the analytical model shows different patterns of relationship between SCI and OP (Figure 3):

(i). When market uncertainty is low and MU takes high value indicating the data cloud is in the low market uncertainty regime. Then, the correlation between SCI and OP as shown in Figure $3 \mathrm{c}$ is clearly modelled as a positive relationship. This is consistent with many mainstream research findings in SCI (D. Prajogo and Olhager 2012; Jin et al. 2013). A large body of lean supply chain management research also represent exactly the point that close partnership and high level of SCI with the first tier suppliers contributes positively to the supply chain's overall performance, while the overall market environment is assumed to be relatively stable.

(ii). When market uncertainty is high and MU takes low value indicating the data cloud is in the high market uncertainty regime. Then, the correlation between SCI and OP in Figure 3a shows a slightly negative correlation. Many extant literatures (Rodrigues et al. 2004; Cousins and Menguc 2006) have also shown findings in a similar vein that SCI does not appear to help much when the supply chain is under a highly volatile market place. Researchers in the area of agile supply chain also echoed their findings in a similar wavelength (Zhang 2011; Vazquez-Bustelo et al. 2007). Essentially an agile supply chain prefers the management approach through virtual net-work rather than vertical integration (Agarwal et al. 2006). Transaction cost theory (Williamson 1981; Parkhe 1993) has long concluded that uncertain market and environmental complexity will lead to higher transaction cost and thus lower economic performance. 
(iii). When market uncertainty is medium and MU takes middle value indicating the data cloud is in the medium market uncertainty regime. Then, the correlation between SCI and OP Figure $3 b$ shows that the relationship between SCI and operational performance is somewhat a mixture and may be difficult to define. This is consistent with the findings from "leagile" supply chain management whereby the market uncertainty is at its transit level between high and low (Agarwal et al. 2006; Goldsby et al. 2006). Research in this transitional regime is very much case sensitive and is largely subject to other contingency factors.

The 3D analytical model (Figure 4) seems to be useful in explaining the inter-play of the three key constructs. The 'non-linear' relationship discovered in this study could add to the literature of supply chain integration by explaining analytically how one of the exogenous factors may moderate or control the effect of the integration on operational performance. Furthermore, the seemingly inconsistent findings from past literatures, in terms of 'no effect', 'positive', 'negative' and 'it depends' (see Appendix A), can now be largely reconciled by the findings trough threshold regression, which perceives the SCI-OP relationship through the lens of the exogenous factors' moderating effect. Therefore, perhaps, no one was wrong after all.

Our interpretation of the study results can also be taken from a structural contingency theory (Stonebraker and Afifi 2004; Sousa and Voss 2008) perspective. External fit can be interpreted as a consistency between the supply chain's internal structure and the operational strategies that response to its external environment. Since market uncertainty is an important part of the external environment, a manufacturer should therefore respond to it by developing, selecting and implementing appropriate strategies to maintain the fit with its external environment (Tushman and Nadler 1978; Hambrick 1983; Kotha and Nair 1995). This is how exactly our research results and the analytical model will implicate to the real-world business practices.

\section{Conclusions and Limitations}

This study contributes to the existing literatures on supply chain integration in two important respects. First, it adds to the literature the moderated effect on supply chain integration by empirically testing the relationship between supply chain integration and operational 
performance under the influence of market uncertainty - an exogenous factor. Second, it establishes analytically the 'non-linear' relationship between supply chain integration and operational performance by applying, probably for the first time, the threshold regression method. Our research also enriches the growing discussion of SCI by sharing empirical findings from automotive industries in China.

We can conclude that two of our developed hypotheses have been positively supported through a rigorous testing process. We critically reviewed the resent literatures in the subject area and identified a number of inconsistencies and research gaps as illustrated in section 2; and our research have substantively filled the research gap by contributing theoretically that the effectiveness of SCI on improving the operational performance is conditioned to, or moderated by the market uncertainty given a specific industrial market.

Based on a properly designed empirical investigation in China's automotive industry, we established the primary data sets through dimensional reduction methods; and the data analysis concludes that the overall pattern of the correlation between the supply chain integration and operational performance tends to be 'non-linear'; and the nature of the "nonlinearity' is significantly influenced or moderated by the market uncertainty as an exogenous environmental factor.

The theoretical implication of the study can be anticipated in the renewed understanding on how supply chain integration may be causally correlated with operational performance under the moderating power of market uncertainty; and as for the practical implication, as mentioned in Section 5, we can expect a more rational decision-making in regards to the supply chain's integration level and the desired competitive performance, and all is in respect to the changing external business environment.

Despite the above claims some limitations can also be observed. Since the data source was initially limited to the China's automotive industry, caution needs to be exercised when considering different cultural environment. Regarding the methodology, this study uses crosssectional design for the threshold regression analysis, thus the time dimension is largely ignored. Although, the CMA (common method bias) test has been applied and it reveals positive outcomes, other systematic bias factors such as uniformity of respondents, regions 
and seasons could still have some bias effects lurking in the data. As one of the future research agenda, a longitudinal study that observe the changes of the measures over time would likely shed new lights to the SCI-OP relationship.

\section{Reference}

Agarwal, A., Shankar, R., \& Tiwari, M. (2006). Modeling the metrics of lean, agile and leagile supply chain: An ANP-based approach. European Journal of Operational Research, 173(1), 211-225.

Aláez-Aller, R., \& Carlos Longás-García, J. (2010). Dynamic supplier management in the automotive industry. International Journal of Operations \& Production Management, 30(3), 312-335.

Andrews, D. W., \& Ploberger, W. (1994). Optimal tests when a nuisance parameter is present only under the alternative. Econometrica: Journal of the Econometric Society, 1383-1414.

Ansaripoor, A. H., Asian, S., Faghih-Roohi, S., Lee, P. T. W., \& Hu, Z. H., (2017). Risk quantification in maritime fleet planning problem: a CVaR approach. Working Paper.

Asian, S., Hemati, M., \& Samandizadeh, K. (2009). Strategic planning evaluation in manufacturing companies through fuzzy analytic hierarchy process (FAHP). Journal of Industrial Management, 4(7), 1-20.

Asian, S., \& Nie, X. (2014). Coordination in supply chains with uncertain demand and disruption risks: Existence, analysis, and insights. IEEE Transactions on Systems, Man, and Cybernetics: Systems, 44(9), 1139-1154.

Asian, S., Ertek, G., Haksoz, C., Pakter, S., \& Ulun, S. (2016). Wind turbine accidents: A data mining study. IEEE Systems Journal. PP(99), 1-12. doi: 10.1109/JSYST.2016.2565818

Bai, J. (1997). Estimation of a change point in multiple regression models. Review of Economics and Statistics, 79(4), 551-563.

Beamon, B. M. (1999). Measuring supply chain performance. International Journal of Operations \& Production Management, 19(3), 275-292.

Boehmke, B. C. \& Hazen, B. T. (2017). "The Future of Supply Chain Information Systems: The Open Source Ecosystem". Global Journal of Flexible Systems Management,18 (2), 163-168.

Bowersox, D. J., Closs, D. J., \& Stank, T. P. (1999). 21st century logistics: making supply chain integration a reality: Michigan State University, Council of Logistics Management, Michigan, USA

Breusch, T. S., \& Pagan, A. R. (1979). A simple test for heteroscedasticity and random coefficient variation. Econometrica: Journal of the Econometric Society, 1287-1294.

Brown, T. A. (2015). Confirmatory factor analysis for applied research: Guilford Press, New York, USA 
Cao, Z., Huo, B., Li, Y., \& Zhao, X. (2015). The impact of organizational culture on supply chain integration: a contingency and configuration approach. Supply Chain Management: An International Journal, 20(1), 24-41.

Chandler, A. D. (1990). Strategy and structure: Chapters in the history of the industrial enterprise, MIT press, Boston, USA.

Coleman, L. (2011). An exploratory analysis of factors influencing initial market response and media reports following shock corporate events. Financial Review, 46(2), 313-336.

Cousins, P. D., \& Menguc, B. (2006). The implications of socialization and integration in supply chain management. Journal of Operations Management, 24(5), 604-620.

Cronbach, L. J. (1951). Coefficient alpha and the internal structure of tests. psychometrika, 16(3), 297-334.

Das, A., Narasimhan, R., \& Talluri, S. (2006). Supplier integration-finding an optimal configuration. Journal of Operations Management, 24(5), 563-582.

Davies, R. B. (2002). Hypothesis testing when a nuisance parameter is present only under the alternative: Linear model case. Biometrika, 484-489.

Devaraj, S., Krajewski, L., \& Wei, J. C. (2007). Impact of eBusiness technologies on operational performance: the role of production information integration in the supply chain. Journal of Operations Management, 25(6), 1199-1216.

Drazin, R., \& Van de Ven, A. H. (1985). Alternative forms of fit in contingency theory. Administrative Science Quarterly, 514-539.

Droge, C., Vickery, S. K., \& Jacobs, M. A. (2012). Does supply chain integration mediate the relationships between product/process strategy and service performance? An empirical study. International Journal of Production Economics, 137(2), 250-262.

Ebrahimi, S. M. (2015). Examining The Impact Of Supply Chain Integration On Organization Structure And Operational Performance in Oil and Gas Supply Chains: A Contingency Approach. University of Sheffield,

Faghih-Roohi, S., Ong, Y. S., Asian, S., \& Zhang, A. N. (2016). Dynamic conditional value-at-risk model for routing and scheduling of hazardous material transportation networks. Annals of Operations Research, 247(2), 715-734.

Farrell, A. M. (2010). Insufficient discriminant validity: A comment on Bove, Pervan, Beatty, and Shiu (2009). Journal of Business Research, 63(3), 324-327.

Flynn, B. B., Huo, B., \& Zhao, X. (2010). The impact of supply chain integration on performance: a contingency and configuration approach. Journal of Operations Management, 28(1), 58-71.

Frohlich, M. T., \& Westbrook, R. (2001). Arcs of integration: an international study of supply chain strategies. Journal of Operations Management, 19(2), 185-200. 
Galbraith, J. R. (1973). Designing complex organizations: Addison-Wesley Longman Publishing Co., Inc.

Germain, R., \& Iyer, K. N. (2006). The interaction of internal and downstream integration and its association with performance. Journal of Business Logistics, 27(2), 29-52.

Gimenez, C., van der Vaart, T., \& Pieter van Donk, D. (2012). Supply chain integration and performance: the moderating effect of supply complexity. International Journal of Operations \& Production Management, 32(5), 583-610, doi:10.1108/01443571211226506.

Gimenez, C., \& Ventura, E. (2005). Logistics-production, logistics-marketing and external integration: their impact on performance. International Journal of Operations \& Production Management, 25(1), 20-38.

Glenn Richey Jr, R., Chen, H., Upreti, R., Fawcett, S. E., \& Adams, F. G. (2009). The moderating role of barriers on the relationship between drivers to supply chain integration and firm performance. International Journal of Physical Distribution \& Logistics Management, 39(10), 826-840.

Goldman, S. L. and Nagel, R.N. (1995). Agile competitors and virtual organizations: strategies for enriching the customer: John Wiley \& Sons, England..

Goldsby, T. J., Griffis, S. E., \& Roath, A. S. (2006). Modeling lean, agile, and leagile supply chain strategies. Journal of Business Logistics, 27(1), 57-80.

Graham, G., Zailani, S., \& Rajagopal, P. (2005). Supply chain integration and performance: US versus East Asian companies. Supply Chain Management: An International Journal, 10(5), 379-393.

Hambrick, D. C. (1983). High profit strategies in mature capital goods industries: A contingency approach. Academy of management journal, 26(4), 687-707.

Hansen, B. E. (1999). Threshold effects in non-dynamic panels: Estimation, testing, and inference. Journal of econometrics, 93(2), 345-368.

Hansen, B. E. (2000). Sample splitting and threshold estimation. Econometrica, 575-603.

He, Y., \& Zhao, X. (2012). Coordination in multi-echelon supply chain under supply and demand uncertainty. International Journal of Production Economics, 139(1), 106-115.

Henrysson, S. (1963). Correction of item-total correlations in item analysis. Psychometrika, 28(2), 211-218.

Huang, M.-C., Yen, G.-F., \& Liu, T.-C. (2014). Reexamining supply chain integration and the supplier's performance relationships under uncertainty. Supply Chain Management: An International Journal, 19(1), 64-78.

Huo, B. (2012). The impact of supply chain integration on company performance: an organizational capability perspective. Supply Chain Management: An International Journal, 17(6), 596-610, 
Jakhar, S. K. (2014). "Designing the green supply chain performance optimisation model". Global Journal of Flexible Systems Management, 15 (3), 235-259.

Jin, Y., Fawcett, A. M., \& Fawcett, S. E. (2013). Awareness is not enough: commitment and performance implications of supply chain integration. International Journal of Physical Distribution \& Logistics Management, 43(3), 205-230.

Jonsson, P., Andersson, D., Boon-itt, S., \& Yew Wong, C. (2011). The moderating effects of technological and demand uncertainties on the relationship between supply chain integration and customer delivery performance. International Journal of Physical Distribution \& Logistics Management, 41(3), 253-276.

Khazaei Pool, J., Asian, S., Arabzad, S.M., Balouei Jamkhaneh, H., \& Kia Lashaki, J. (2017a). Development of a model to analyze the factors affecting RFID technology acceptance in small and medium-sized enterprises. International Journal of Services and Operations Management, Forthcoming.

Khazaei Pool, J., S., Arabzad, Asian, S., Fahimi, M., \& Verij Kazemi, R. (2017b). Employing fuzzy ANP for ranking the personality of international brands in the sports shoe industry, Journal of Modelling in Management, Forthcoming: DOI: 10.1108/JM2-02-2016-0009

Kim, S. W. (2009). An investigation on the direct and indirect effect of supply chain integration on firm performance. International Journal of Production Economics, 119(2), 328-346.

Koenker, R., \& Bassett Jr, G. (1982). Robust tests for heteroscedasticity based on regression quantiles. Econometrica: Journal of the Econometric Society, 43-61.

Kotha, S., \& Nair, A. (1995). Strategy and environment as determinants of performance: evidence from the Japanese machine tool industry. Strategic management journal, 16(7), 497-518.

Koufteros, X., Vonderembse, M., \& Jayaram, J. (2005). Internal and external integration for product development: the contingency effects of uncertainty, equivocality, and platform strategy. Decision Sciences, 36(1), 97-133.

Lambert, D. M., \& Cooper, M. C. (2000). Issues in supply chain management. Industrial marketing management, 29(1), 65-83.

Lawrence, P. R., \& Lorsch, J. W. (1967). Managing differentiation and integration. Organization and environment.

Li, G., Yang, H., Sun, L., \& Sohal, A. S. (2009). The impact of IT implementation on supply chain integration and performance. International Journal of Production Economics, 120(1), 125138, doi:10.1016/j.ijpe.2008.07.017.

Li, J., Ning, L., Zeng, D., \& Gu, X. (2014). Dynamic patterns of technology collaboration: a case study of the Chinese automobile industry, 1985-2010. Scientometrics, 101(1), 663-683. 
Liu, Z., \& Cruz, J. M. (2012). Supply chain networks with corporate financial risks and trade credits under economic uncertainty. International Journal of Production Economics, 137(1), 55-67.

Lockstroem, M., Schadel, J., Harrison, N., Moser, R., \& Malhotra, M. K. (2010). Antecedents to supplier integration in the automotive industry: a multiple-case study of foreign subsidiaries in China. Journal of Operations Management, 28(3), 240-256.

Longinidis, P., \& Georgiadis, M. C. (2013). Managing the trade-offs between financial performance and credit solvency in the optimal design of supply chain networks under economic uncertainty. Computers \& Chemical Engineering, 48, 264-279 Mozur, P. (2014). China Auto Firms Catch Up. Wall Street Journal (Online), 1-1.

Narasimhan, R., \& Kim, S. W. (2002). Effect of supply chain integration on the relationship between diversification and performance: evidence from Japanese and Korean firms. Journal of Operations Management, 20(3), 303-323.

Neely, A., Gregory, M., \& Platts, K. (1995). Performance measurement system design: a literature review and research agenda. International Journal of Operations \& Production Management, 15(4), 80-116.

Parkhe, A. (1993). Strategic alliance structuring: A game theoretic and transaction cost examination of interfirm cooperation. Academy of management journal, 36(4), 794-829.

Paul, S. K., Asian, S., Goh, M., \& Torabi, S. A. (2017). Managing sudden transportation disruptions under delivery delay and quantity loss. Annals of Operations Research, Forthcoming.

Petersen, K. J., Handfield, R. B., \& Ragatz, G. L. (2005). Supplier integration into new product development: coordinating product, process and supply chain design. Journal of Operations Management, 23(3), 371-388.

Prajogo, D., \& Olhager, J. (2012). Supply chain integration and performance: The effects of long-term relationships, information technology and sharing, and logistics integration. International Journal of Production Economics, 135(1), 514-522.

Prajogo, D. I., Oke, A., \& Olhager, J. (2015). Supply chain processes: linking supply logistics integration, supply performance, lean processes and competitive performance. International Journal of Operations \& Production Management.

Rai, A., Patnayakuni, R., \& Seth, N. (2006). Firm performance impacts of digitally enabled supply chain integration capabilities. MIS quarterly, 225-246.

Rodrigues, A. M., Stank, T. P., \& Lynch, D. F. (2004). Linking strategy, structure, process, and performance in integrated logistics. Journal of Business logistics, 25(2), 65-94.

Russell, J. A. (1978). Evidence of convergent validity on the dimensions of affect. Journal of personality and social psychology, 36(10), 1152. 
Saeed, K. A., Malhotra, M. K., \& Grover, V. (2005). Examining the impact of interorganizational systems on process efficiency and sourcing leverage in buyer-supplier dyads. Decision Sciences, 36(3), 365-396.

Schreiber, J. B., Nora, A., Stage, F. K., Barlow, E. A., \& King, J. (2006). Reporting structural equation modeling and confirmatory factor analysis results: A review. The Journal of educational research, 99(6), 323-338.

Scott, W. R., \& Cole, R. E. (2000). The Quality Movement and Organizational Theory: Sage.

Sezen, B. (2008). Relative effects of design, integration and information sharing on supply chain performance. Supply Chain Management: An International Journal, 13(3), 233-240.

Shalender, K. \& Singh, N. (2015). "Marketing flexibility: Significance and implications for automobile industry". Global Journal of Flexible Systems Management, 16 (3), 251-262.

Sharifkhani, M., Khazaei Pool, J., \& Asian, S. (2016). The impact of leader-member exchange on knowledge sharing and performance: An empirical investigation in the oil and gas industry. Journal of Science and Technology Policy Management, 7(3), 289-305.

Sinha, K. K., \& Van de Ven, A. H. (2005). Designing work within and between organizations. Organization Science, 16(4), 389-408.

Somarin, A. R., Asian, S., Jolai, F., \& Chen, S. (2017a). Flexibility in service parts supply chain: a study on emergency resupply in aviation MRO. International Journal of Production Research, Forthcoming.

Somarin, A. R., Chen, S., Asian, S., \& Wang, D. Z. (2017b). A heuristic stock allocation rule for repairable service parts. International Journal of Production Economics, 184, 131-140.

Somarin, A. R., Asian, S., \& Chen, S. (2016, December). Dynamic priority repair policy for service parts supply chain. In Industrial Engineering and Engineering Management (IEEM), 2016 IEEE International Conference on (pp. 798-802). IEEE.

Song, M., \& Di Benedetto, C. A. (2008). Supplier's involvement and success of radical new product development in new ventures. Journal of operations management, 26(1), 1-22.

Sousa, R., Oliveira, P., van der Vaart, T., Pieter van Donk, D., Gimenez, C., \& Sierra, V. (2012). Modelling the integration-performance relationship: Collaborative practices, enablers and contextual factors. International Journal of Operations \& Production Management, 32(9), 1043-1074.

Sousa, R., \& Voss, C. A. (2008). Contingency research in operations management practices. Journal of Operations Management, 26(6), 697-713.

Stank, T. P., Keller, S. B., \& Closs, D. J. (2001). Performance benefits of supply chain logistical integration. Transportation Journal, 32-46. 
Stonebraker, P. W., \& Afifi, R. (2004). Toward a contingency theory of supply chains. Management Decision, 42(9), 1131-1144.

Stratton, R., \& Warburton, R. D. (2003). The strategic integration of agile and lean supply. International Journal of Production Economics, 85(2), 183-198.

Swink, M., Narasimhan, R., \& Wang, C. (2007). Managing beyond the factory walls: effects of four types of strategic integration on manufacturing plant performance. Journal of Operations Management, 25(1), 148-164.

Swink, M., \& Song, M. (2007). Effects of marketing-manufacturing integration on new product development time and competitive advantage. Journal of Operations Management, 25(1), 203-217.

Tan, S. (2009). Misuses of KR-20 and Cronbach's alpha reliability coefficients. Egitim ve Bilim, 34(152), 101.

Tavakoli, M. R., Asian, S., \& Hemati, M. (2012). Using a fuzzy MADM in the Balanced SCORE card for the performance improvement in Iranian steel industries. Iranian Journal of Trade Studies (IJTS), 16(61), 51-80.

Terjesen, S., Patel, P. C., \& Sanders, N. R. (2012). Managing Differentiation-Integration Duality in Supply Chain Integration*. Decision Sciences, 43(2), 303-339.

Thompson, J. D. (1967). Organizations in action: Social science bases of administrative theory: Transaction publishers.

Turkulainen, V. (2008). Managing cross-functional interdependencies - the contingent value of integration: Teknillinen korkeakoulu.

Turkulainen, V., \& Ketokivi, M. (2012). Cross-functional integration and performance: what are the real benefits? International Journal of Operations \& Production Management, 32(4), 447467.

Tushman, M. L., \& Nadler, D. A. (1978). Information Processing as an Integrating Concept in Organizational Design. Academy of management Review, 3(3), 613-624.

Tyagi, M., Kumar, P. \& Kumar, D. (2015). "Assessment of critical enablers for flexible supply chain performance measurement system using fuzzy DEMATEL approach". Global Journal of Flexible Systems Management,16(2), 115-132.

Van der Vaart, T., \& van Donk, D. P. (2008). A critical review of survey-based research in supply chain integration. International Journal of Production Economics, 111(1), 42-55.

Van Hoek, R. I. (1998). "Measuring the unmeasurable"-measuring and improving performance in the supply chain. Supply Chain Management: An International Journal, 3(4), 187-192. 
Vazquez-Bustelo, D., Avella, L., \& Fernández, E. (2007). Agility drivers, enablers and outcomes: empirical test of an integrated agile manufacturing model. International Journal of Operations \& Production Management, 27(12), 1303-1332.

Vickery, S. K., Jayaram, J., Droge, C., \& Calantone, R. (2003). The effects of an integrative supply chain strategy on customer service and financial performance: an analysis of direct versus indirect relationships. Journal of Operations Management, 21(5), 523-539.

Wilden, R., Gudergan, S. P., Nielsen, B. B., \& Lings, I. (2013). Dynamic capabilities and performance: strategy, structure and environment. Long Range Planning, 46(1), 72-96.

Williams, L. J., Hartman, N. \& Cavazotte, F. (2010). "Method variance and marker variables: A review and comprehensive CFA marker technique". Organizational Research Methods, 13(3), 477-514.

Williamson, O. E. (1981). The economics of organization: The transaction cost approach. American journal of sociology, 548-577.

Williamson, O. E. (1989). "Transaction cost economics". Handbook of industrial organization, 1, 135182.

Won Lee, C., Kwon, I.-W. G., \& Severance, D. (2007). Relationship between supply chain performance and degree of linkage among supplier, internal integration, and customer. Supply Chain Management: An International Journal, 12(6), 444-452.

Wong, C. Y., Boon-Itt, S., \& Wong, C. W. (2011). The contingency effects of environmental uncertainty on the relationship between supply chain integration and operational performance. Journal of Operations Management, 29(6), 604-615.

Wong, E. M., Ormiston, M. E., \& Tetlock, P. E. (2011). The effects of top management team integrative complexity and decentralized decision making on corporate social performance. Academy of management journal, 54(6), 1207-1228.

Wook Kim, S. (2006). Effects of supply chain management practices, integration and competition capability on performance. Supply Chain Management: An International Journal, 11(3), 241248.

Xinqiao, P. \& Junfeng, W. (2001). A Study of Market Size and Enterprise Quantity of China's Auto Industry [J]. Economic Research Journal, 11, 006.

Yu, W., Chavez, R., Feng, M., \& Wiengarten, F. (2014). Integrated green supply chain management and operational performance. Supply Chain Management: An International Journal, 19(5/6), 683-696, doi:10.1108/scm-07-2013-0225.

Yusuf, Y., Gunasekaran, A., Adeleye, E., \& Sivayoganathan, K. (2004). Agile supply chain capabilities: Determinants of competitive objectives. European Journal of Operational Research, 159(2), 379-392. 
Zhang, D. Z. (2011). Towards theory building in agile manufacturing strategies - Case studies of an agility taxonomy. International Journal of Production Economics, 131(1), 303-312.

Zhao, G., Feng, T., \& Wang, D. (2015). Is more supply chain integration always beneficial to financial performance? Industrial marketing management, 45, 162-172.

Zhao, L., Huo, B., Sun, L., \& Zhao, X. (2013). The impact of supply chain risk on supply chain integration and company performance: a global investigation. Supply Chain Management: An International Journal, 18(2), 115-131.

\section{Appendix A. Summary of literature on the relationship between SCI and performance}

\begin{tabular}{lllc} 
Author & Year & Journal & Relationship \\
\hline (Stank et al.) & 2001 & TJ & No effect \\
(Vickery et al.) & 2003 & JOM & No effect \\
(Rodrigues et al.) & 2004 & JBL & No effect \\
(Gimenez and Ventura) & 2005 & IJOPM & Positive \\
(Koufteros et al.) & 2005 & DS & Negative \\
(Rai et al.) & 2006 & MIS & Positive \\
(Cousins and Menguc) & 2006 & JOM & No effect \\
(Das et al.) & 2006 & JOM & Inverse V-shape \\
(Wook Kim) & 2006 & SCMAIJ & Positive \\
(Devaraj et al.) & 2007 & JOM & It depends \\
(Swink and Song) & 2007 & JOM & Negative \\
(Van der Vaart and van Donk) & 2008 & IJPE & Positive \\
(Sezen) & 2008 & SCMAIJ & Positive \\
(Glenn Richey Jr et al.) & 2009 & IJPDLM & Positive \\
(Kim) & 2009 & IJPE & Positive \\
(G. Li et al.) & 2009 & IJPE & Positive \\
(Flynn et al.) & 2010 & JOM & Positive \\
(Jonsson et al.) & 2011 & IJPDLM & Positive \\
(C. Y. Wong et al.) & 2011 & JOM & Positive \\
(Gimenez et al.) & 2012 & IJOPM & It depends \\
(Huo) & 2012 & SCMAIJ & Positive \\
(D. Prajogo and Olhager) & 2012 & IJPE & Positive \\
(Sousa et al.) & 2012 & IJOPM & It depends \\
(Turkulainen and Ketokivi) & 2012 & IJOPM & It depends \\
(Terjesen et al.) & 2012 & DS & Inverse U-shape \\
(Jin et al.) & 2013 & IJPDLM & Positive \\
(Huang et al.) & 2014 & SCMAIJ & Positive \\
(Yu et al.) & 2014 & SCMAIJ & Positive \\
\hline
\end{tabular}

TJ: Transportation Journal

JOM: Journal of Operations Management

JBL: Journal of Business Logistics

IJOPM: International Journal of Operations \& Production Management

DS: Decision Sciences 
MIS: MIS Quarterly

SCMAIJ: Supply Chain Management: An International Journal

IJPE: International Journal of Production Economics

IJPDLM: International Journal of Physical \& Distribution Logistic Management

Research findings summary of reviewed articles. 


\section{Appendix B. Measurement items (with factor loading)}

Supply chain integration (eigenvalue $=4.311$ ). Please indicate the extent of integration or joint activities or information sharing between your organisation and your major $1^{\text {st }}$-tier supplier in the following areas $(1=$ not at all; $7=$ extensive $)$

The level of strategic partnership with your key suppliers 0.846

The participating level of your suppliers in the design and planning stage

Collaboration and coordination level through all your internal functions

You share your customer demand forecasting with your internal planning and scheduling

Synchronising your suppliers' capacity with your internal production and customer demand

The level of information gathering from your customers through information network

0.862

Operational performance (eigenvalue $=3.073$ ). Please indicate the degree to which you agree to the following statements concerning your company's performance with respect to your major customer (1 $=$ strongly disagree; $7=$ strongly agree)

\begin{tabular}{lc}
\hline Your company can quickly modify your products to meet your customer's requirement & 0.773 \\
Your company can quickly introduce new products into the market & 0.829 \\
The lead time for fulfilling your customers' order is short & 0.747 \\
Your company can quickly respond to the changes in the market & 0.809 \\
Your company provides a high level of customer service & 0.758
\end{tabular}

Market uncertainty (eigenvalue $=2.423$ ). Please indicate the degree to which you agree to the following statements concerning the market uncertainty with respect to your primary/major products $(1=$ strongly disagree; 7 = strongly agree $)$

The market demand for your major products in terms of volume is stable

Your product sales pattern over different seasons in a year is predictable

Customer anticipation for the products' features and functions is always known.

Technological innovation arisen from competitors' products will have no impact on the market of your

0.775 product 